\section{Giant chest wall arteriovenous malformation with spinal cord compression}

Sir,

Congenital arteriovenous malformations (AVMs) may occur in any organ. Skin AVMs are common, but AVMs of the chest wall or extradural space are uncommon. We report a patient with an extensive AVM that involved skin, chest wall, and extradural space. Definitive treatment of such an AVM is difficult.

A 23-year-old man presented with progressive lower extremity weakness. A large cutaneous 'haemangioma' of the right chest posterior wall measuring $22 \mathrm{~cm}$ in greatest diameter had been present since birth (figure 1). There was no history of ulceration, bleeding, or rapid increase in size. Underlying soft tissues of the chest wall were involved. The AVM was easily compressed and it rapidly refilled. Neurological examination showed generalised weakness of both lower extremities. The right plantar response was extensor; left plantar response was flexor.

Laboratory investigations were normal. Chest radiograph showed deformity of the right 6th through 10th ribs. Chest computed tomography (CT) showed a large vascular mass involving the skin, chest wall, pleura, and posterior mediastinum of the right chest (figure 2). CT myelogram showed extension of this mass into the extradural space at the T-6 level. The neural foramen was enlarged.

At midthoracic laminectomy a very vascular extradural mass was removed, confirmed to be a benign arteriovenous malformation. ${ }^{1}$ The patient made a complete neurological recovery. Because of the extent of the AVM, definitive surgical excision of the chest wall and mediastinal components was not recommended. Embolisation will be reserved for recurrence of symptoms.

Chest wall ${ }^{2}$ and extradural ${ }^{3}$ AVMs are uncommon. Extradural AVMs are usually located in the mid-thoracic region. They may extend into the mediastinum and paraspinal areas in a 'dumb bell' fashion but involve-

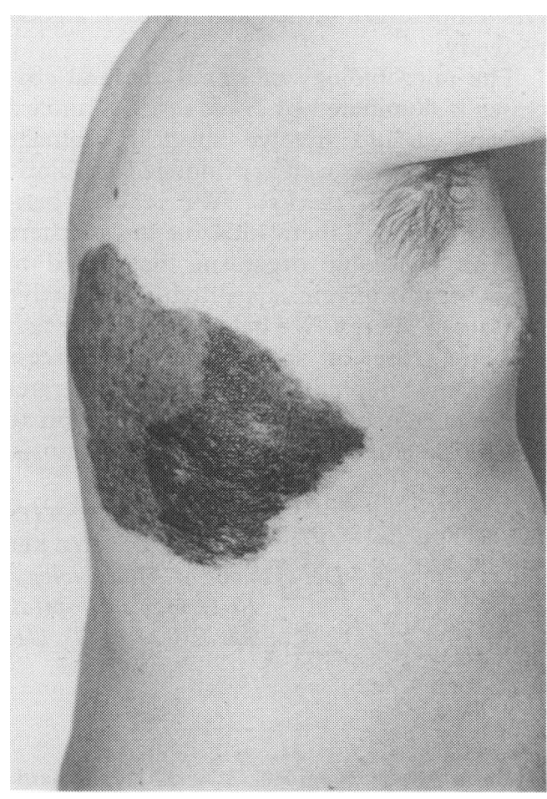

Figure 1 Chest wall arteriovenous malformation

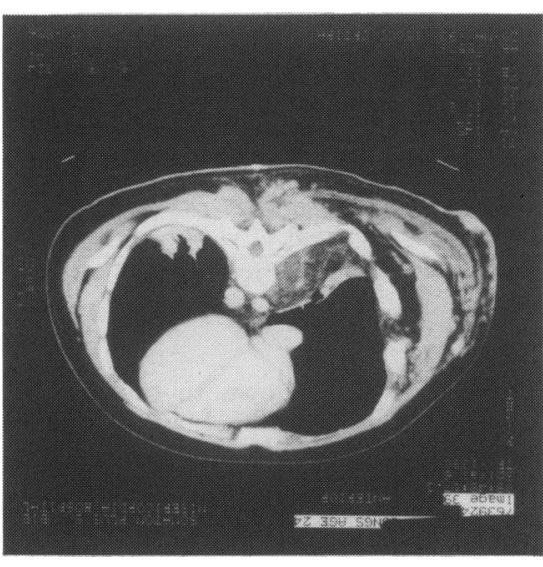

Figure 2 CT of the chest and spine shows a large vascular mass involving chest wall, mediastinum, and extradural space

ment of the chest wall is rare. ${ }^{3,4}$ Our patient's AVM was much more extensive than any previously reported case.

Extradural AVMs with cord compression require neurosurgical intervention. ${ }^{3}$ Extradural AVM resection usually has a favourable outcome, but excessive operative haemorrhage is a potential hazard. Careful operative haemostasis is required to prevent worsening of cord compression by extradural haematoma.

Indications for treatment of chest wall AVMs include disfigurement, bleeding, and congestive heart failure. Small chest wall AVMs can be cured by excision ${ }^{2}$ but complete resection of extensive chest wall AVMs is problematic. Our patient's AVM could not have been resected without sacrificing approximately $50 \%$ of his chest wall. Intraoperative haemorrhage can be massive in these circumstances. In addition, radical surgical extirpation does not always result in permanent AVM control; recurrence may still occur. ${ }^{5}$ Arterial embolisation is the treatment of choice for very large AVMs that are symptomatic. ${ }^{1}$ Embolisation provides control of large chest wall AVMs but permanent cure is infrequent. Since embolisation is primarily palliative in cases of large chest wall AVMs, it should probably be reserved for symptomatic patients.

JOHN D URSCHEL ROBERT W BROAD Department of Surgery, University of Alberta, Edmonton, Alberta, Canada

Correspondence to JD Urschel, Division of Thoraci Surgery, Roswell Park Cancer Institute, Elm an Carlton Streets, Buffalo, NY 14263-0001, USA

1 Allison DJ, Kennedy A. Peripheral arteriovenous malformations. BMF 1991; 303: $1191-4$ 2 Winchester DJ, Victor TA, Fry WA. Intercosta hemangioma presenting as a chest wall tumor. Ann Thorac Surg 1992; 54: 145-6.

3 Hillman J, Bynke O. Solitary extradural cavernous hemangiomas in the spinal canal: report of five cases. Surg Neurol 1991; 36: 19-24.

4 Padovani R, Tognetti F, Proietti D, Pozzati E Servadei F. Extrathecal cavernous hemangioma. Surg Neurol 1982; 18: 463-5.

5 Friehs I, Koch G. Congenital giant arteriovenous malformation in a 31-year-old male. Thorac Cardiovasc Surg 1991; 39: 110-2.

\section{Benign spontaneous pneumoperitoneum in an elderly patient treated medically with recovery}

Sir

Spontaneous pneumonoperitoneum signals perforation of a hollow viscus in over $90 \%$ of cases $^{1}$ and patients usually undergo emergency surgery. However, in the absence of sepsis or peritonitis and in the presence of co-existing illnesses often seen in the elderly, laparotomy and an anaesthetic might sometimes actually compromise the chance of survival. It has been suggested that these patients can often be treated without laparotomy provided that abdominal tap is negative for sepsis or inflammatory fluid. ${ }^{2}$

A frail 93-year-old with no medical history apart from her arthritis for which she took ibuprofen, was admitted with a short history of abdominal pain and diarrhoea. On examination, the abdomen was distended but there was little tenderness and she was apyrexial. Abdominal X-ray showed massive pneumoperitoneum. The surgeons recommended conservative measures. She was treated with intravenous fluids and antibiotics. Her pneumoperitoneum resolved and she was eventually discharged home without the actual cause being determined.

Pneumoperitoneum without peritonitis is a distinct entity ${ }^{3}$ which does not require urgent surgical intervention, but may cause diagnostic confusion and sometimes cause unnecessary laparotomy. It has been described secondary to ruptured pneumatoides cystoides intestinales, ${ }^{4}$ pneumomediastinum, pneumothorax, and sometimes following endoscopic procedures such as percutaneous endoscopic gastrostomy. ${ }^{5}$ Hence a careful history and exclusion of other causes may prevent a hazardous surgery in elderly patients with this condition.

A HUSSAIN JGC COX

Department of Medicine, Wansbeck General Hospital, Northumberland, UK

1 McGlone PB, Vivion CG, Meir L. Spontaneous pneumoperitoneum. Gastroenterology 1966; 51 393-8.

2 Gutkin Z, Ieuin A, Meged S, Sorkine P, Geller E. Spontaneous pneumoperitoneum without peritonitis. Int Surg 1992; 77: 219-22.

3 Daly BP, Guthrie JA, Couse NF. Pneumoperitoneum without peritonitis. Postgrad Med $f$ 1991; 67: 999-1003.

4 Samach M, Bradent LJ, Bernstein LH. Spontaneous preums cyeous preumoperitoneum with pneumatoids in a patient with mixed 1978; 69: 494-500. Am f Gastroenterol

5 Pidala MJ, Slezak FA, Porter JA. Pneumoperitoneum following percutaneous endoscopic gastrostomy. Surg Endosc 1992; 6: 128-9.

Pneumoperitoneum: causes

- pneumatoides cystoides intestinales

- pneumomediastinum

- pneumothorax

- following percutaneous endoscopic gastrostomy

- peritoneal dialysis

- following laparotomy 